NOTICE: this is the author's version of a work that was accepted for publication in Ecological Modelling. Changes resulting from the publishing process, such as peer review, editing, corrections, structural formatting, and other quality control mechanisms may not be reflected in this document. Changes may have been made to this work since it was submitted for publication. A definitive version was subsequently published in Ecological Modelling, Volume 249, January 2013, Pages 59-67, http://dx.doi.org/10.1016/j.ecolmodel.2012.07.004 


\title{
Using microalgae for combined lipid production and heavy metal removal from leachate
}

\author{
$\underline{\text { R.G. Richards }}^{\text {a }}$ and B. Mullins ${ }^{\text {b,c,d }}$ \\ Griffith Centre for Coastal Management (GCCM), Griffith University, Queensland \\ School of Public Health, Curtin University, Western Australia \\ Fluid Dynamics Research Group, Curtin University, Western Australia \\ Atmospheric Environment Research Centre (AERC), Griffith University, Queensland \\ Email: r.richards@griffith.edu.au
}

\begin{abstract}
The remediation of leachate from (municipal) landfills and disposal of hypersaline effluent (from desalination plants) are becoming an increasing challenge for many government authorities and practitioners. There is mounting interest in using bioremediation as a means of stripping contaminants from these waste streams and in the potential for lipid production using microalgae. We present a system dynamics approach to exploring the efficacy of using mixed microalgae populations to treat leachate-hypersaline water. This model evaluates the temporal evolution of metal removal and lipid production using four common marine microalgae species: Nanochloropsis, Pavlova lutheri, Tetraselmis chuii and Chaetoceros muelleri. The uptake kinetics of the metals (removal from the leachate) are modelled using basic adsorption kinetics and the model is primarily parameterised from data obtained through an experimental study where two photobioreactors were dosed with composite leachate-hypersaline solution and seed with the four microalgae species. After a ten-day period, the microalgae population was found to have removed over $95 \%$ of the metals from the solution. Microalgae growth was dominated by N. gaditana and C. muelleri, which are the two species with the highest lipid contents. Overall, this study indicated that the use of microalgae-based bioremediation is a viable method for treating waste streams and lipid-production.
\end{abstract}

Keywords: dynamic modelling, microalgae, leachate remediation, heavy metals, desalination

\section{Introduction}

Landfills are a common means of solid waste disposal in both municipal and industrial waste treatment. In Australia, approximately half of all waste generated in 2006-2007 was disposed of in landfills (EPHC, 2009). Furthermore, ca. 60\% of all Australian municipal waste generated during this same period was disposed in landfills (EPHC, 2009). These levels are indicative of waste disposal characteristics in many other countries (EEA, 2007).

There is an increasing awareness that this treatment method is not a sustainable approach to solid waste disposal (EEA, 2007). As waste in a landfill breaks down, it releases gaseous (typically methane) and liquid (leachate) by products. In order to reduce costs and increase sustainability of landfills, energy recovery is typically preferred, usually through methane combustion engines. However, energy recovery from leachate is not usually practised. 
Leachate is due to both rainwater percolation through the landfill and the breakdown of usually putrescible materials in the landfill. Leachate is typically composed of organic matter, decomposition products, organic chemicals and dissolved metals (Xu et al., 2008; Vedrenne et al., 2012). As such, there is concern over the deleterious effects that this leachate can have on the surrounding environment (EEA, 2007). For this reason, leachate must be contained and treated. This has resulted in considerable effort into exploring the efficacy of various leachate mitigation / management methods including conventional aerobic or anaerobic treatment methods (Ana-Maria and Maria, 2010; Kurniawan et al., 2010; Sunil et al., 2011). While such treatment methods are capable of producing leachate of suitable quality for reuse or disposal, they are highly energy intensive and do not allow the potential for value-adding through recovery of metals or lipid production from the wastewater.

It has been shown that many species of microalgae are suited to the processing of nutrient-rich wastewater sources and these commonly produce high lipid yields (e.g. Prathima Devi et al., 2011; Jiang et al., 2011). In addition, microalgae are known vectors of metal uptake (bioaccumulation), which can allow efficient removal of metals from wastewater streams (Boke and Seda, 2010). However, the use of microalgae as a treatment method and cost-recovery option for landfill leachate has received relatively little attention (Cheung et al., 1993; Lin et al., 2007; Elena et al., 2010).

A key challenge to using microalgae as a remediation option is that many microalgae are sensitive to the toxicity of lechate pollutants. Cheung et al., (1993) examined the toxicity of landfill leachate on four freshwater microalgal species and found that the leachate inhibited the growth of all algae species tested. However, microalgae which inhabit more saline water have been shown to commonly exhibit greater resilience and robustness than freshwater species, when exposed to adverse conditions (Rodolfi et al., 2009). That marine species of microalgae appear more suitable than freshwater species for leachate treatment has a potential additional benefit for the management of hypersaline water produced by desalination plants. Desalination plants must frequently store hypersaline water if salinity in the disposal area becomes too high and therefore could be potentially combined with municipal leachate to reduce salinity. A further advantage is the prevention of contamination of the process. Leachate could be expected to contain biota that would compete with any microalgal species introduced, requiring prior disinfection of the leachate (if freshwater algal species are to be used) and risking subsequent recontamination. This is negated by introducing saline conditions for the leachate.

To understand treatment systems that can reliably treat leachate using microalgae, it is important to develop models that allow exploration of the dynamic relationships that exists between microalgae growth dynamics (and hence lipid production), metal adsorption and toxicity. This work provides a novel approach to simultaneously treating landfill leachate and hypersaline desalination effluent for coastal regions. We employ a system dynamics approach (Sterman, 2000), so that the nonlinearities, feedback pathways and time lags that characterise environmental systems can be investigated. System dynamics provides a holistic framework for building comprehension and scoping of environmental problems (Costanza and Ruth, 1998). This work investigates the potential of combining landfill leachate with hypersaline water, and simultaneously treating both waste streams using a mixed culture of marine microalgal species. In order to accurately quantify the dynamics of such systems, it is essential to model the metals uptake from leachate, and the impact this 
has on growth rates and mortality. This paper will focus on the use of system modelling techniques to explore the dynamics of such systems.

\section{Materials and Methods}

\subsection{Experimental set-up}

Representative municipal leachate samples were obtained from the leachate holding ponds of an operating (West Australian) landfill. The leachate was allowed to settle to remove any solid/particulate matter and then filtered using a 2 micron filter. The resulting supernatant was then used for the experiments. The raw leachate was then characterised with respect to Biological Oxygen Demand (BOD), Chemical Oxygen Demand (COD), total organic content (TOC) and metals (via Inductively Coupled Plasma - Mass Spectrometry) (Table 1).

Two cylindrical photo-bioreactors were utilised in the experimental work. The operating volume of reactor 1 (R1) was $2.5 \mathrm{l}$ and the volume of reactor 2 (R2) was 12.5 l. Three 5,000K (natural white) fluorescent lamps were fitted to R1 and four lamps were fitted to R2 and both bioreactors were covered with an external layer of reflective material to improve overall light intensity and uniformity. The lamps were illuminated for 12 hours in each $24 \mathrm{hr}$ period to simulate a 12:12 (light:dark) duty cycle. This was principally done to simulate the light conditions in a system illuminated by natural light, however, such cycles may have other benefits (Janssen 2002). The light intensity profile within the two bioreactors was measured using a LX-101 Lux Meter. Air was injected into the bottom of each reactor to ensure complete mixing and provide a suitable growth environment. The air-flow rates used were $1250 \mathrm{ml} \mathrm{min}^{-1}$ and $3250 \mathrm{ml} \mathrm{min}^{-1}$ for R1 and R2 respectively.

Four species of marine microalgae (Nanochloropsis gaditana, Pavlova lutheri, Tetraselmis chuii and Chetoceros muelleri) were used in the reactors. A mixed culture was selected as it was not known which species were most suited to growth within the leachate. A $50 \mathrm{ml}$ solution of each species was added to the reactor, following the addition of the leachate and an artificial sea-salt mixture, used to simulate the mixture of leachate and hypersaline desalination water. The artificial sea-salt mix (Aquasonic) was added at a rate sufficient to ensure that the same salinity as typical seawater (ca. $30 \mathrm{~g} \mathrm{l}^{-1}$ ). The temperature in the two reactors was measured as $34.6{ }^{\circ} \mathrm{C}$ and $26.1^{\circ} \mathrm{C}$ for $\mathrm{R} 1$ and R2 respectively. Heating of the reactors was provided by the fluorescent lamps alone resulting in an elevated temperature for $\mathrm{R} 1$ compared to $\mathrm{R} 2$ due to the difference in reactor size. Conversely, the temperature of R2 was only $2.1^{\circ} \mathrm{C}$ above room temperature. During non-illuminating phases, both reactors would decrease to $24{ }^{\circ} \mathrm{C}$. A partial cover was used on the reactor to minimise evaporation.

At the conclusion of the experiments, the algae was separated from the liquor by filtration and analysed for species composition (counts) as well as metals and lipid content.

\subsection{Model Description}

A simple microalgae-detritus model is used to explore the adsorption kinetics of six metals and the growth dynamics of four algal species in the leachate (Figure 1). Equations and parameter values used in the model are presented in Table 2.

Algal growth is based on the maximum growth rates ( $\mu_{\mathrm{MAX}}$ ) specified for each of the four microalgae species. These are adjusted for the multiplicative effects of 
temperature (fT) and light (fL) while it is assumed here that nutrients are not limiting to growth throughout the experimental period. This assumption is taken because there is no data on the nutrient concentrations in the reactors. Furthermore, municipal leachate is typically high in dissolved inorganic nutrients (Wang et al. 2010). Individual growth is adjusted to account for the light-dark (12 hours on: 12 hours off) illumination cycle described in the experimental section by assuming no light limitation effect during the 'day' cycle and 100\% limitation during the 'night' cycle. A global background mortality rate $\left(\right.$ mort $\left._{20}\right)$ is assumed for the four microalgae species as these have been shown to be similar across algae species (Bowie et al., 1985).

The effect of temperature on microalgae growth is modelled using a skewed normal distribution used by Lehman et al., (1975), chosen because the optimum temperature for algal growth (see Table 2) is lower than the operating temperature of the batch reactors (see Table 3). This approach allows the growth inhibition that occurs when the leachate temperature is above optimum growth temperatures $\left(\mathrm{T}_{\mathrm{opt}}\right)$ to be accounted for. We assumed a minimum growth temperature $\left(\mathrm{T}_{\min }\right)$ for this function at $0^{\circ} \mathrm{C}$ for all four microalgae species. The $\mathrm{Q}_{10}$ formulation was used to adjust the referenced mortality and remineralisation rate constants to the operating temperatures.

Dead algae (detritus) is included as a state variable in the model even though it does not contribute to the growth dynamics of the microalgae (in the model). This is because the system is not assumed to be nutrient-limited and therefore remineralisation of the detritus to $\mathrm{NH}_{4}{ }^{+}, \mathrm{NO}_{\mathrm{X}}$ and $\mathrm{PO}_{4}{ }^{-2}$ and subsequent uptake by the microalgae is not modelled. However, detritus dynamics are included to provide an indication of its net production within the two reactors and subsequent contribution to the dissolved inorganic nutrient pool.

\subsection{Metal Adsorption}

Each metal was represented in the model as a 'free' (non-adsorbed) concentration along with the respective concentrations adsorbed to each of the four microalgal species, necessitating the use of 30 state variables. The adsorption of metals to the four microalgal species was estimated by assuming that adsorption was a product of the free metal concentration, a metal-specific adsorption rate $\left(\mathrm{AR}_{\mathrm{j}}\right)$ and the proportion of each microalgae species relative to the combined concentration of the four species. $\mathrm{AR}_{\mathrm{j}}$ is constant across the four different microalgae species and therefore is only dependent on the relative proportions of each species. It was assumed here that metal adsorption was not limited by the availability of binding sites on the microalgae. $A_{\mathrm{j}}$ (adjusted for temperature effects) were specified through calibration for each of the metals.

Metals are known to inhibit microalgae growth in leachate (Cheung et al., 1993). The potential toxicity of metals on microalgal growth in the leachate is related here to the total concentration of the six metals adsorbed to each algal species rather than individual effects because the metal-algae specific data to enable this to be achieved does not exist. The potential combined toxic effect of metals on growth was modelled by assuming an additive effect of background mortality (mort 20 ) and metal-related mortality ( mort $_{\mathrm{Me}}$ ), with the total mortality effect adjusted for temperaturedependency.

\subsection{Initial Conditions}

The initial concentrations of microalgae and metals equal to the concentrations measured during the experimental process (refer Table 3). The initial detritus 
concentration is assumed to be $0 \mathrm{mg} \mathrm{l}^{-1}$ as the leachate was pre-filtered. Detritus is assumed to also remineralise into dissolve inorganic constituents as determined by the rate constant $\left(\min _{20}\right)$.

\subsection{Calibration}

The model was calibrated to the initial and end concentrations of the six metals and four microalgae species. The six metal-specific adsorption rates $\left(\mathrm{AR}_{\mathrm{j}}\right)$ and four microalgae-specific mortality rates ( mort $_{\mathrm{Me}}$ ) were adjusted to fit the model to the data. These 10 parameters $\left(\mathrm{AR}_{1-6}\right.$ and mort $\left.\mathrm{Me}, 1-4_{4}\right)$ are not correlated and therefore can be successfully obtained through fitting. Calibration was carried out separately for each reactor because the model has insufficient complexity (because of the paucity of data) to simultaneously calibrate against the two datasets.

\section{Results}

The initial and final concentrations of the four algal species and the six metals measured in the two reactors are summarised in Table 3.

\subsection{Experimental Reactors}

Light measurements conducted on the two reactors indicated that they were both reasonably illuminated throughout the column (Figure 2). However, the illumination was not entirely consistent, rather it was characterised by higher lux levels near the surface and lower near the bottom of the reactor.

In terms of microalgae growth dynamics, all four species increased their concentration over the experimental period with the exception of T. chuii in R2, which had zero concentration at the end. Additionally, T. chuii had the lowest net growth in R1. N. gaditana and C. muelleri showed the greatest growth in R1, increasing from their initial concentration by $1100 \%$ and $1500 \%$ respectively while in R2, N. gaditana and P. lutheri were the biggest growers, increasing their initial concentration by $11150 \%$ and $7400 \%$ respectively.

All of the metals were observed to decrease in concentration compared to their initial concentration. In both R1 and R2, concentrations of Ce and La were observed to decrease to zero while Fe and Al decreased by over 95\% compared to their initial concentrations. Conversely, Mn (29\% for R1 and 66\% for R2) and Ba (49\% for R1 and $76 \%$ for R2) had the lowest removal efficiencies of the tested metals.

\subsection{Simulations}

The systems model was successfully fitted to the experimental data by minimising the least squares error between measurement and prediction through adjusting the parameters for metal adsorption rate $\left(\mathrm{AR}_{\mathrm{j}}\right)$ and metal-related mortality ( mort $\left._{\mathrm{Me}, \mathrm{i}}\right)$. Note that for the aqueous concentrations of Ce and La (R1 and R2) and T. chuii (R2) were recorded as zero concentrations at the end of the experiment. No data was available on how quickly (within the experimental timeframe) Ce, La and T. chuii disappeared from the aqueous solution. For the purpose of this modelling exercise, it was assumed that these three constituents of the leachate did not reach zero concentration until right to the end of the experiment.

The simulated microalgae concentrations for each reactor are shown in Figure 3. The effect of the 12:12 (light:dark) illumination cycle can be seen in most of the microalgae. For example, C. muelleri, which has the highest maximum growth rate, exhibits a clear distinction between net growth (light) and net loss (dark) periods. 
Conversely, the model predicts that $\mathrm{T}$. chuii (R2) rapidly decreases to almost zero after 120 hours and there is no visible evidence of growth periods.

The calibrated values of mort $_{\text {Me-Alg }}$ indicate the relative sensitivity of each microalgal species to the total concentration of metals. With the exception of P. lutheri, the metal-specific mortality rate was generally higher for R2 than R1. Overall, P. lutheri

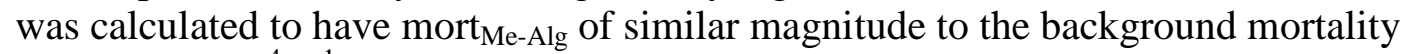
rate $\left(1.25 \times 10^{-4} \mathrm{~h}^{-1}\right)$ for both reactors.

Model predictions on the algal growth dynamics in the reactor are presented in Figure 3. These are characterised by exponential growth of each species over the 10 day experimental period. Strongest growth (observed and predicted) was observed for N. gaditana and C. muelleri with both species reaching a concentration of ca. $900 \mathrm{mg} \mathrm{l}^{-1}$ after 10 days. Notably lower concentrations were observed for P. lutheri (ca. $300 \mathrm{mg}$ $\mathrm{l}^{-1}$ ) and T. chuii (ca. $100 \mathrm{mg} \mathrm{l}^{-1}$ ).

The metal speciation predictions provided by the model are presented in Figure 4. These output plots indicate that the decrease in metal concentrations observed during the experiment work could be replicated by the model. They also suggest that at least $75 \%$ of $\mathrm{Al}, \mathrm{Ce}, \mathrm{Fe}$ and $\mathrm{La}$ are removed from the leachate after 120 hours of the 240 hour exposure period. Furthermore, it appears that the removal of $\mathrm{Mn}$ and $\mathrm{Ba}$ from the leachate are more gradual and linear processes.

Figure 4 also shows that the distribution of each metal between the four microalgae species is generally dominated by N. gaditana. The proportion of each metal adsorbed to P. lutheri and C. muelleri are comparable whilst the lowest proportion is adsorbed to T. chuii. This reflects the modelling approach used of relating metal adsorption to the proportional concentrations of the four microalgae species.

The model predictions for the metal concentrations in the reactor are presented in Figure 3. The aqueous concentration of Fe and Mn (and also for $\mathrm{Ba}$, Ce and La) decreases exponentially as these respective metals are drawn from the water column and adsorbed to the four algal species. For Fe (Figure 3), metal adsorption was predicted in the model to be dominated by C. muelleri while for Mn (Figure 3), Ba and Ce the metal adsorption was more evenly distributed amongst the four algal species. These observations were consistent for both reactor environments.

\section{Discussion}

We have presented here a system dynamics model that has been developed to help understand the combined dynamics of microalgae growth, metal adsorption and metal toxicity. This has been undertaken as a means of understanding the efficacy of using microalgae as a saline water - municipal leachate remediation approach. The potential value-adding of using microalgae for lipid production has also been assessed.

\subsection{Heavy metal removal}

Overall, this appears a viable means of simultaneously treating both landfill leachate and disposing of hypersaline desalination water. Furthermore, it may provide useful lipids, provided leachate volumes are sufficient and the microalgal and subsequent lipid separation can be conducted efficiently. The combined microalgae population generally showed excellent uptake of the metals, with over $95 \%$ of the metals removed from the solution.

$\mathrm{Fe}$ and $\mathrm{Al}$ represented the predominant metals (by mass) in the raw leachate and their almost complete removal indicates the effectiveness of using microalgae to treat the 
solution. In high pH solutions, Fe and $\mathrm{Al}$ typically exist as $\mathrm{Fe}(\mathrm{III})$ and $\mathrm{Al}(\mathrm{III})$ states. $\mathrm{Fe}(\mathrm{III})$ is broadly unavailable for active uptake by microalgae because it is dominated by complexes formed with organic ligands (Sunda and Huntsman, 1998). Al(III) also has reduced solubility (and hence bioavailability) because it undergoes strong hydrolysis (Morris et al., 1986). However, potential biological reduction of Fe(III) and $\mathrm{Al}$ (III) to more soluble forms could be occurring in the leachate leading to biological uptake by the microalgae.

Lanthanum and cerium were completely removed from the leachate although the initial concentration was much lower than for the other metals. There is little evidence of algae previously being used for this purpose, however seaweed has been shown to successively remove rare earth metals like La and Ce from wastewater (e.g. Palmieri et al., 2002).

$\mathrm{Mn}$ and Ba had the lowest extraction efficiency out of the six metals tested. The relatively poor extraction of Mn from the leachate could reflect the effects of redox state on microalgae bioavailability. While Mn(II) is highly soluble and readily available for uptake, the thermodynamically stable states of $\mathrm{Mn}$ (III) and $\mathrm{Mn}$ (IV) are insoluble and therefore unavailable for direct uptake (Sunda and Huntsman, 1998). Conversely, the uptake of Ba uptake appears to be strongly dependent on the presence of Fe precipitates adsorbed to the cell surface (Sternberg et al., 2005). This may reflect a general paucity of these precipitates and support the supposition that the Fe is being transformed to the $\mathrm{Fe}(\mathrm{II})$ redox state.

\subsection{Microalgae growth dynamics}

At the end of the experimental period, the mixed microalgae population in both reactors was dominated by Nanochloropsis gaditana and Chetoceros muelleri. These two microalgae species also have the highest lipid contents (refer Table 2), which indicates that the lipid-producing capacity of the mixed microalgae population is strong. Conversely, Tetraselmis sp., which is known to dominate mixed culture systems (pers. comm. Simon Longbottom, Curtin Aquaculture Laboratory), performed comparatively poorly. Rather, Tetraselmis chuii was observed to exhibit the lowest concentration out of the four algal species. However, the maximum growth rates $\left(\mu_{\mathrm{MAX}}\right)$ listed for each of the four microalgae species in Table 2 indicates that $\mathrm{T}$. chuii would perform poorly under the experimental conditions. Specifically, $\mu_{\mathrm{MAX}}$ $\left(0.46 \mathrm{~d}^{-1}\right)$ for T. chuii was more than $50 \%$ lower than for the other three species. Conversely, $\mu_{\operatorname{MAX}}\left(1.7 \mathrm{~d}^{-1}\right)$ for C. muelleri was at least $70 \%$ higher than for the other three species, suggesting that it would grow faster. Furthermore, the optimum growth temperature $\left(\mathrm{T}_{\mathrm{opt}}\right)$ for $\mathrm{C}$. muelleri was closer to the operating temperatures than for the other three. Interestingly, N. gaditana outperformed Pavlova lutheri even though they share similar values for $\mu_{\mathrm{MAX}}$ and $\mathrm{T}_{\mathrm{opt}}$, indicating that the former is more resilient to the toxicity of the metals in the leachate than the latter.

\subsection{System Dynamics Modelling}

The system dynamics modelling approach provided a means for exploring algal growth dynamics of a multi-species mixture and their ability to adsorb a suite of metals whilst also considering the potential effects of metal toxicity on growth. A better understanding of the 'cross' dynamics of metal adsorption and the accompanying toxic effect on growth dynamics are important considerations here. By using basic microalgal growth functions (growth, mortality, temperature effect, light limitation) and introducing a simple relationship to represent the limiting effect of 
metal toxicity on mortality, we were able to match the start and end concentrations of each of the four algal species.

The calculated proportion of microalgae mortality that was attributed to the toxic effects of the metals indicated that T. chuii and C. muelleri were the most sensitive. Cheung et al., (2011) observed that T. chuii was very sensitive to a suite of metals, which could be why this microalgae performed the worst in terms of growth. Conversely, the metal-related mortality rates for P. lutheri and N. gaditana were broadly an order of magnitude lower than the other two species, indicating resilience towards the potential toxicity of the leachate.

The metal-specific adsorption rates were higher for the metals ( $\mathrm{Al}, \mathrm{Ce}, \mathrm{Fe}, \mathrm{La}$ ) that were completely, or almost completely, removed from the leachate. The kinetics of metal sorption (adsorption and absorption) are complex and dependent on a large suite of biogeochemical determinants (Schmitt et al., 2001). In particular, metal adsorption and uptake is strongly dependent on metal-specific speciation characteristics as already highlighted elsewhere in the discussion. Furthermore, there is evidence that increased metal removal efficiency is attained when multispecies microalgae populations are used (Li et al., 2011). However, increased metal removal has also been shown to strongly correlate with biomass (Li et al., 2011) and therefore supports the approach used here in the model to relate adsorption to biomass fractions.

\subsection{Model Limitations}

The absence of data across the experimental period entails that the functional form of the growth curves for the microalgae species is not verified here. However, exponential growth curves, which were observed for all species except T. chuii, are commonly observed in microalgae species under non-limiting or weakly limited conditions (e.g. Leonardos and Geider, 2004). The simplicity of the model and the relative dearth of parameterising data entailed that the model has major assumptions. The use of aggregate term to represent toxic effect of adsorbed metals on the different microalgae species was used because of the absence of metal-algae concentrations for each of the metals. This approach does not allow the toxicities of the individual metals, or different combinations of the different metals, on microalgae dynamics to be fully explored. The effect of metal toxicity will also likely impact on both growth rates and mortality rates whereas we have elected to focus on the effect on mortality rate only. The assumptions of no nutrient limitation and either complete or nil light limitation (depending on the dark:light cycle) are also coarse simplifications. The former was selected because of the absence of nutrient data and the assumption that the nutrient concentrations in the leachate would be high. The latter was selected because it was assumed that the illumination methodology used in the experiment would supply enough light for photosynthesis during the light cycle and that the absence of light during the dark cycle would completely inhibit photosynthesis. We did, however, explicitly model the effect of temperature on growth and mortality rates using standard adjustment algorithms.

\subsection{Management implications}

Overall, we have shown that microalgae are a viable means of treating leachate and hypersaline water for disposal. We have also highlighted that lipids and heavy metals can be theoretically recovered for energy and re-use if economically viable.

The method we have proposed will be suited to landfills in coastal areas, in particular, those co-located with desalination plants. The main advantage of this demonstrated 
method is robustness because the hypersalinity of the desalination effluent will likely inactivate deleterious organisms in both the desalination liquor and the raw leachate. This will ensure the dominance of more desirable micro-organisms. One apparent disadvantage of this system is precludes of treated leachate without desalination.

From a decision-making and optimisation contexts, such system dynamics modelling can provide an insight into the efficacy of leachate management in terms of maximising the available resources (or minimising the use of resources used). This is a practical challenge for decision makers when confronted with leachates that comprise of variable (dynamic) mixed contaminants that can affect the ability of the microalgae species extracting the contaminants. However, it is also important to highlight that numerical models are ultra-simplifications of reality and therefore what they can deliver can always by improved.

\section{Acknowledgments}

The authors would like to acknowledge research funding from the (Perth) Eastern Metropolitan Regional Council. The authors would also like to acknowledge the assistance of Mr Simon Longbottom (Manager of the Curtin Aquaculture Laboratory) and Mr Xiao Hua. 


\section{REFERENCES}

Ana-Maria, S., Maria, G., 2010. Municipal solid waste landfilling and treatment of resulting liquid effluents. Environmental Engineering and Management Journal 9, 993-1019.

Boke, O.H., Seda, T.Z., 2010. Assessment of various parameters of metal biology in marine microalgae Phaeodactylum Tricornutum and Dunaliella Tertiolecta. Fresenius Environmental Bulletin 19(12A), 2981-2986.

Bowie, G.L., Mills, W.B., Porcella, D.B., Campbell, C.L., Pagenkopf, J.R., Rupp, G.L., Johnson, K.M., Chan, P.W.H., Gherini, S.A., Chamberlain, C.E., 1985. Rates, constants, and kinetics formulations in surface water quality modeling (Second Edition). Environmental Research Laboratory Office of Research and Development U.S. Environmental Protection Agency.

Cheung, K.C., Chu, L.M., Wong, M.H., 1993. Toxic effect of landfill leachate on microalgae. Water Air and Soil Pollution. 69, 337-349.

Christi, Y. 2007. "Biodiesel from microalgae”, Biotechnol. Adv. 25, 294-306.

Costanza, R., Ruth, M., (1998). Using Dynamic Modeling to Scope Environmental Problems and Build Consensus. Environmental Management 22, 183-195

EEA 2007 Europe's environment: the fourth assessment. European Environmental Agency Rept. No. 10 EEA, Copenhagen, Ch 6, pp251-289.

Elena, L., Vishwanath, P., Elin, G., 2010. Efficient Purification of Heavy-MetalContaminated Water by Microalgae-Activated Pine Bark. Water Air and Soil Pollution 210, 493-500.

EPHC, 2009 National Waste Overview 2009. Environmental Protection and Heritage Council, November 2009.

Forján, E., Garbayo, I., Casal, C., Vílchez C., 2007. Enhancement of carotenoid production in Nannochloropsis by phosphate and sulphur limitation. Communicating Current Research and Educational Topics and Trends in Applied Microbiology A. Méndez-Vilas (Ed.)

Goldman, J.C., 1986. On phytoplankton growth rates and particulate C:N:P ratios at low light. Limnology and Oceanography 31, 1358-1363.

Hiemstra, T., van Riemsdijk, W.H. 2006. Biogeochemical speciation of Fe in ocean water. Marine Chemistry 102, 181-197.

Janssen, M.G.J., 2002. Cultivation of microalgae: effect of light/dark cycles on biomass yield. Thesis Wageningen University, Wageningen, The Netherlands 184p http://www.bpe.wur.nl/nr/rdonlyres/450c58df-a0d2-4954-bb77d0677325e981/65655/proefscriftmjanssen.pdf

Jiang, L., Luo, S., Fan, X., Yang, Z., Guo, R., 2011. Biomass and lipid production of marine microalgae using municipal wastewater and high concentration of $\mathrm{CO}_{2}$. Applied Energy 88, 3336-3341.

Kurniawan, T.A., Lo, W., Chan, C., Sillanpää, M.E.T., 2010. Biological processes for treatment of landfill leachate. Journal of Environmental Monitoring 12, 20322047. 
Lehman, J.T., Botkin, D.B., Likens, G.E., 1975. The assumptions and rationales of a computer model of phytoplankton population dynamics. Limnology and Oceanography 20, 343-364.

Leonardos, N., Geider, R.J., 2004. Effects of nitrate:phosphate supply ratio and irradiance on the C:N:P stoichiometry of Chaetoceros muelleri. Eur.J. Phycol. 39, 173-180.

Li, S-P., Li, J-T., Kuang, J-L., Duan, H-N., Zeng, Y., Shu, W-S., 2011. Effects of species richness on cadmium removal efficiencies of algal microcosms. Journal of Applied Ecology 49, 261-267.

Lin L., Chan G.Y.S., Jiang B.L., Lan, C.Y., 2007. Use of ammoniacal nitrogen tolerant microalgae in landfill leachate treatment. Waste Management 27, 1376-1382.

Liu, G., Chai, X., Shao, Y., Hu, L., Xie, Q., Wu, H., 2011. Toxicity of copper, lead, and cadmium on the motility of two marine microalgae Isochrysis galbana and Tetraselmis chui. Journal of Environmental Sciences 23, 330-335

Morris, A.W., Howland, R.J.M., Bale, A.J., 1986. Dissolved aluminium in the Tamar Estuary, southwest England. Geochimica et Cosmochimica Acta 50, 189-197.

Oltra, R., Todolí, R., Bosque, T., Lubián, L.M., Navarro, J.C., 2000. Life history and fatty acid composition of the marine rotifer Synchaeta cecilia valentina fed different algae. Marine Ecology Progress Series 193, 125-133.

Palmieri, M.C., Volesky, B., Garcia Jr., O., 2002. Biosorption of lanthanum using Sargassum fluitans in batch system. Hydrometallurgy 67, 31-36.

Prathima Devi, M., Venkata Subhash, G., Venkata Mohan, S., 2011. Heterotrophic cultivation of mixed microalgae for lipid accumulation and wastewater treatment during sequential growth and starvation phases: Effect of nutrient supplementation. Renewable Energy 43, 276-283.

Rodolfi, L., Zittelli, G.C., Bassi, N., Padovani, G., Biondi, N., Bonini, G., Tredici, M.R., 2009. Microalgae for Oil: Strain Selection, Induction of Lipid Synthesis and Outdoor Mass Cultivation in a Low-Cost Photobioreactor. Biotechnology and Bioengineering 102, 100-112.

Schmitt, D., Müller, A., Csögör, Z., Frimmel, F.H., Posten, C., 2001. The adsorption kinetics of metal ions onto different microalgae and siliceous earth. Water Research 35, 779-785.

Steele, J.H., 1962. Environment control of photosynthesis in the sea. Limnology and Oceanography 7, 137-150.

Sternberg, E., Tang, D., Ho, T-Y., Jeandel, C., Morel, F.M.M., 2005. Barium uptake and adsorption in diatoms. Geochimica et Cosmochimica Acta, 69, 2745-2752.

Sunil, K., Chart, C., Ackmez, M., 2011. Bioreactor landfill technology in municipal solid waste treatment: An overview. Critical Reviews in Biotechnology 31, 77-97.

Vedrenne, M., Vasquez-Medrano, R., Prato-Garcia, D., Frontana-Uribe, B.A., Ibanez, J.G., 2012. Characterization and detoxification of a mature landfill leachate using a combined coagulation-flocculation/photo Fenton treatment. Journal of Hazardous Materials. 205-206, 208-215.

Vijayaraghavan, K., Sathishkumar, M., Balasubramanian, R., 2011. Interaction of rare earth elements with a brown marine alga in multi-component solutions. Desalintaion 265, 54-59. 
Wang, L., Min, M., Li, Y., Chen, P., Chen, Y., Liu, Y., Wang, Y., Ruan, R., 2010. Cultivation of green algae Chlorella sp. in different wastewaters from municipal wastewater treatment plant. Applied Biochemistry and Biotechnology 162, 1174-86.

Xu, Y., Zhou, Y., Wang, D., Chen, S., Liu, J., Wang, Z., 2008. Occurrence and removal of organic micropollutants in the treatment of landfill leachate by combined anaerobic-membrane bioreactor technology. Journal of Environmental Sciences 20, 1281-1287. 
TABLES

Table 1. Characterisation of the raw municipal leachate

\begin{tabular}{cc}
\hline Leachate Constituent & Concentration \\
\hline DO & $3 \mathrm{mg} \mathrm{l}^{-1}$ \\
COD & $1008 \mathrm{mg} \mathrm{l}^{-1}$ \\
TOC & $668 \mathrm{mg} \mathrm{l}^{-1}$ \\
Aluminium & $33560 \mu \mathrm{g} \mathrm{l}^{-1}$ \\
Iron & $15370 \mu \mathrm{g} \mathrm{l}^{-1}$ \\
Manganese & $270 \mu \mathrm{g} \mathrm{l}^{-1}$ \\
Barium & $175 \mu \mathrm{g} \mathrm{l}^{-1}$ \\
Cerium & $7 \mu \mathrm{g} \mathrm{l}^{-1}$ \\
Lanthanum & $3 \mu \mathrm{g} \mathrm{l}^{-1}$ \\
\hline
\end{tabular}


Table 2. Model Parameters and Equations

\begin{tabular}{|c|c|c|}
\hline Parameter & Value & Reference \\
\hline \multirow[t]{4}{*}{$\mu_{\text {MAX }}$ (maximum growth rate; $\mathrm{d}^{-1}$ ) } & 1.02 (P. lutheri) & Goldman (1986) \\
\hline & 0.46 (T. chuii) & Oltra et al. (2000) \\
\hline & 1.7 (С. muelleri) & $\begin{array}{l}\text { Leonardos \& Geider } \\
\text { (2004) }\end{array}$ \\
\hline & $1.0($ N. gaditana $)$ & Forján et al (2007) \\
\hline \multirow{4}{*}{$\mathrm{T}_{\text {opt }}$ (optimum temperature for growth; ${ }^{\circ} \mathrm{C}$ ) } & 19.2 (P. lutheri) & Christi (2007) \\
\hline & 20-28 (T. chuii) & Christi (2007) \\
\hline & 30 (С. muelleri) & Christi (2007) \\
\hline & 20 (N. gaditana) & Christi (2007) \\
\hline \multirow[t]{4}{*}{ Lipid (lipid content) } & 0.12 (P. lutheri) & Christi (2007) \\
\hline & 0.17 (T. chuii) & Christi (2007) \\
\hline & 0.30 (C. muelleri) & Christi (2007) \\
\hline & 0.54 (N. gaditana) & Christi (2007) \\
\hline $\mathrm{T}_{\min }\left(\right.$ lower lethal limit for microalgae; ${ }^{\circ} \mathrm{C}$ ) & 0 & assumed \\
\hline mort $_{20}$ (background mortality rate; $\mathrm{h}^{-1}$ ) & 0.000125 & Bowie et al., (1985) \\
\hline $\min _{20}$ (remineralisation rate; $\mathrm{h}^{-1}$ ) & 0.00071 & Bowie et al., (1985) \\
\hline $\mathrm{AR}_{\mathrm{j}}$ (metal-specific adsorption rate; $\mathrm{h}^{-1}$ ) & \multicolumn{2}{|l|}{ calibrated } \\
\hline mort $_{\mathrm{Me}}\left(\right.$ metal-related mortality rate; $\mathrm{h}^{-1}$ ) & \multicolumn{2}{|l|}{ calibrated } \\
\hline Equation & \multicolumn{2}{|l|}{ Definition } \\
\hline$\frac{\mathrm{d}\left[\mathrm{ALG}_{\mathrm{i}}\right]}{\mathrm{dt}}=$ uptake $_{\mathrm{i}}-$ mortality $_{\mathrm{i}}$ & \multicolumn{2}{|c|}{ Microalgae concentration for species $i$} \\
\hline$\frac{\mathrm{d}[\mathrm{DET}]}{\mathrm{dt}}=\sum$ mortality $_{\mathrm{i}}-$ min eralisation & \multicolumn{2}{|c|}{ Detritus concentration } \\
\hline$\frac{\mathrm{d}\left[\operatorname{Metal}_{\mathrm{F}, \mathrm{j}}\right]}{\mathrm{dt}}=-\sum$ adsorb $_{\mathrm{Me}-\mathrm{ALG}, \mathrm{ji}}$ & \multicolumn{2}{|c|}{$\begin{array}{l}\text { Free-metal concentration for metal species } \\
\text { and metal-microalgae complex } j i(i= \\
\text { microalgae species, } j=\text { metal })\end{array}$} \\
\hline$\frac{\mathrm{d}\left[\text { MetalALG }_{\mathrm{ij}}\right]}{\mathrm{dt}}=$ adsorb $_{\mathrm{Me}-\mathrm{ALG}, \mathrm{ji}}$ & \multicolumn{2}{|c|}{$\begin{array}{l}\text { Adsorbed metal complex for microalgae } \\
\text { species } i\end{array}$} \\
\hline $\operatorname{adsorb}_{\mathrm{Me}-\mathrm{ALG}, \mathrm{ji}}=\operatorname{Metal}_{\mathrm{F}, \mathrm{j}} \times \mathrm{AR}_{\mathrm{j}} \times \frac{\mathrm{ALG}_{\mathrm{i}}}{\sum \mathrm{ALG}}$ & \multicolumn{2}{|c|}{ Adsorption of metal $j$ to microalgae species $i$} \\
\hline uptake $_{\mathrm{i}}=\mu_{\mathrm{MAX}} \times \mathrm{fL} \times \mathrm{fT} \times \mathrm{ALG}_{\mathrm{i}}$ & \multicolumn{2}{|c|}{ Nutrient uptake rate $\left[\mu \mathrm{g} \mathrm{l}^{-1} \mathrm{~d}^{-1}\right]$} \\
\hline mortality $_{\mathrm{i}}=\left(\right.$ mort $_{20}+$ mort $\left._{\mathrm{Me}}\right) \times \mathrm{fT} \times \mathrm{ALG}_{\mathrm{i}}$ & \multicolumn{2}{|c|}{ Mortality rate of microalgae $\left[\mu \mathrm{g} \mathrm{l}^{-1} \mathrm{~d}^{-1}\right]$} \\
\hline min eralisation $=\min _{20} \times \mathrm{fT} \times \mathrm{DET}$ & \multicolumn{2}{|c|}{ Mineralisation rate - detritus $\left[\mu \mathrm{g} \mathrm{l}^{-1} \mathrm{~d}^{-1}\right]$} \\
\hline
\end{tabular}




\begin{tabular}{|l|l|}
\hline $\mathrm{fT}=\exp \left(-2.3 \times\left(\frac{\mathrm{T}-\mathrm{T}_{\mathrm{opt}, \mathrm{i}}}{\mathrm{T}_{\mathrm{min}, \mathrm{i}}-\mathrm{T}_{\mathrm{opt}, \mathrm{i}}}\right)^{2}\right)$ & $\begin{array}{l}\text { Temperature function used for microalgae } \\
\text { growth }\end{array}$ \\
\hline $\mathrm{fT}=\exp \left(\frac{\mathrm{T}-\mathrm{T}_{\text {ref }}}{10} \times \operatorname{Ln}(2)\right)$ & $\begin{array}{l}\text { Temperature function used to adjust } \\
\text { mortality and mineralisation rate constants }\end{array}$ \\
\hline $\mathrm{fL}=1: 0(12: 12$ hour duty cycle $)$ & Light limitation for microalgae growth \\
\hline
\end{tabular}


Table 3. Initial and final conditions for the bioreactors. End values were determined post-removal of algae.

\begin{tabular}{|c|c|c|c|c|}
\hline \multirow[t]{2}{*}{ Constituent } & \multicolumn{2}{|c|}{ Reactor 1} & \multicolumn{2}{|c|}{ Reactor 2} \\
\hline & Initial & End & Initial & End \\
\hline \multicolumn{5}{|c|}{ Microalgae concentration (cells $\mathrm{ml}^{-1}$ ) } \\
\hline Pavlova lutheri & $3 \times 10^{5}$ & $1.8 \times 10^{6}$ & $6 \times 10^{4}$ & $4.5 \times 10^{6}$ \\
\hline Tetraselmis chuii & $3 \times 10^{5}$ & $6 \times 10^{5}$ & $6 \times 10^{4}$ & 0 \\
\hline Chaetoceros muelleri & $3 \times 10^{5}$ & $4.8 \times 10^{6}$ & $6 \times 10^{4}$ & $1.5 \times 10^{6}$ \\
\hline Nanochloropsis gaditana & $4 \times 10^{5}$ & $4.8 \times 10^{6}$ & $8 \times 10^{4}$ & $9 \times 10^{6}$ \\
\hline \multicolumn{5}{|c|}{ Metal concentration $\left(\mu \mathrm{g} I^{-1}\right)$} \\
\hline Aluminium & 33560 & 970 & 33560 & 1130 \\
\hline Iron & 15370 & 683 & 15370 & 68 \\
\hline Manganese & 270 & 192 & 270 & 93 \\
\hline Barium & 175 & 89 & 175 & 42 \\
\hline Cerium & 7 & 0 & 7 & 0 \\
\hline Lanthanum & 3 & 0 & 3 & 0 \\
\hline \multicolumn{5}{|c|}{ Chemical-physical properties of the leachate solutions } \\
\hline Volume (l) & \multicolumn{2}{|c|}{2.5} & \multicolumn{2}{|c|}{12.5} \\
\hline Temperature $\left({ }^{\circ} \mathrm{C}\right)$ & \multicolumn{2}{|c|}{34.6} & \multicolumn{2}{|c|}{26.1} \\
\hline $\mathrm{pH}$ & \multicolumn{2}{|c|}{$8.44-8.63$} & \multicolumn{2}{|c|}{7.85} \\
\hline Light (Lux) & \multicolumn{2}{|c|}{$1230-37700$} & \multicolumn{2}{|c|}{$414-10780$} \\
\hline
\end{tabular}


Table 4. Calibration parameters (Units for all listed parameters are $\mathbf{h}^{-1}$ )

\begin{tabular}{lcc}
\hline Parameter & Reactor 1 & Reactor 2 \\
\hline $\mathrm{AR}_{\mathrm{Al}}$ & $1.463 \times 10^{-2}$ & $1.431 \times 10^{-2}$ \\
$\mathrm{AR}_{\mathrm{Fe}}$ & $1.294 \times 10^{-2}$ & $2.130 \times 10^{-2}$ \\
$\mathrm{AR}_{\mathrm{Mn}}$ & $1.420 \times 10^{-3}$ & $4.400 \times 10^{-3}$ \\
$\mathrm{AR}_{\mathrm{Ba}}$ & $2.820 \times 10^{-3}$ & $5.948 \times 10^{-3}$ \\
$\mathrm{AR}_{\mathrm{Ce}}$ & $2.600 \times 10^{-2}$ & $3.900 \times 10^{-2}$ \\
$\mathrm{AR}_{\mathrm{La}}$ & $3.000 \times 10^{-2}$ & $4.500 \times 10^{-2}$ \\
mort $_{\text {Me-T.chuii }}$ & $1.163 \times 10^{-3}$ & $3.021 \times 10^{-2}$ \\
mort $_{\text {Me-P.lutheri }}$ & $7.687 \times 10^{-4}$ & $9.609 \times 10^{-4}$ \\
mort $_{\text {Me-C.muelleri }}$ & $7.875 \times 10^{-3}$ & $1.346 \times 10^{-2}$ \\
mort $_{\text {Me-N.gaditana }}$ & $3.844 \times 10^{-4}$ & $2.114 \times 10^{-3}$ \\
\hline
\end{tabular}




\section{FIGURES}

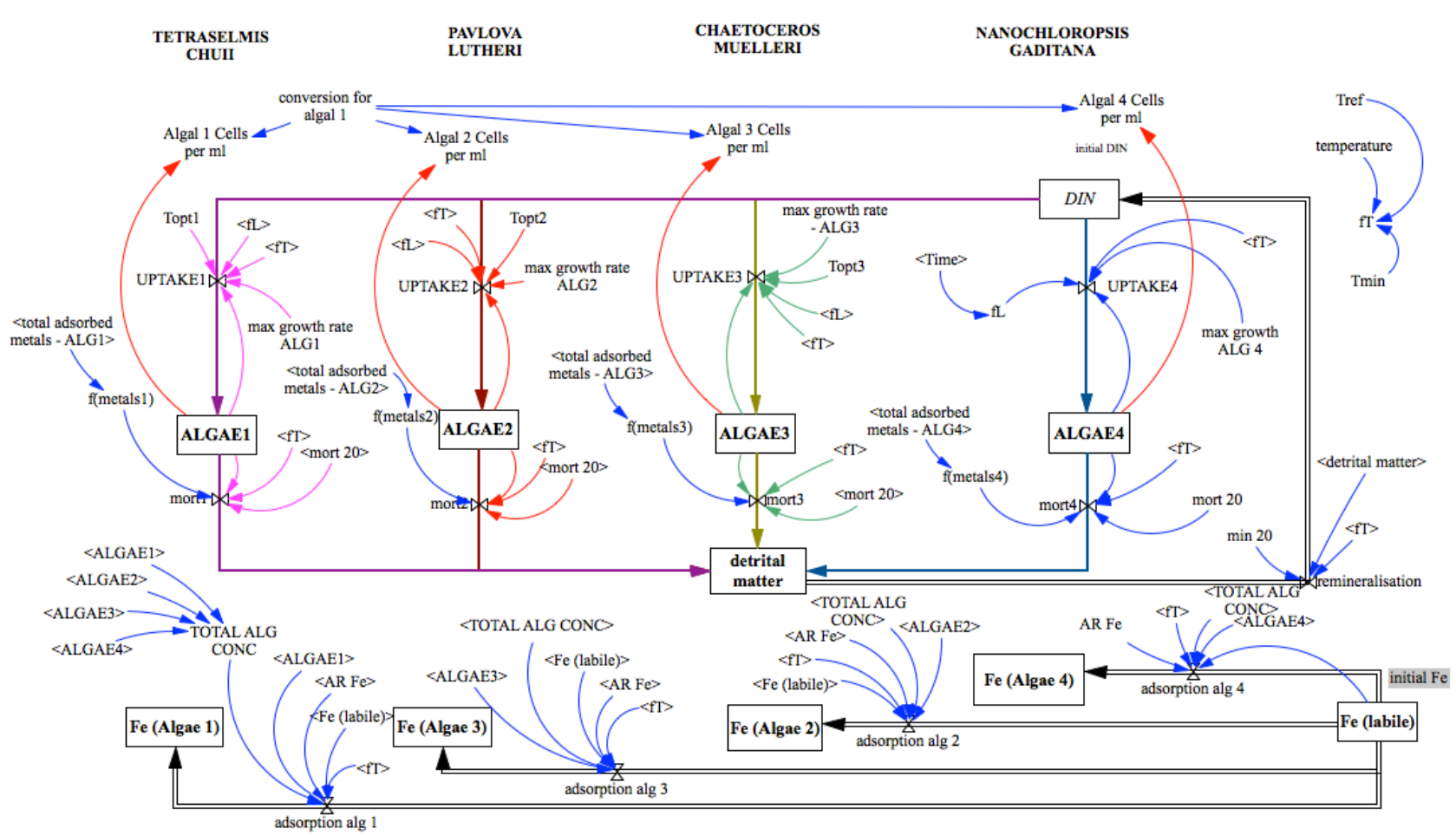

Figure 1. Conceptual model of a single photobioreactor - metal kinetics only shown for iron $(\mathrm{Fe})$. 


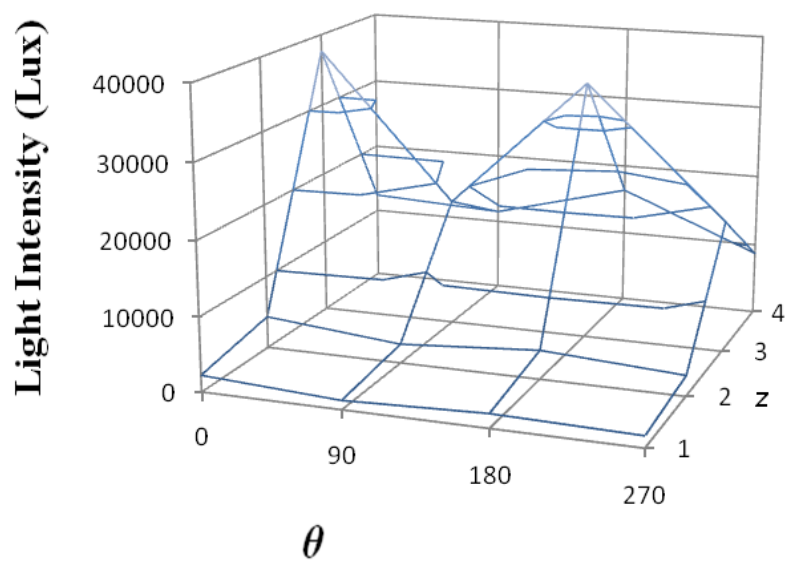

$\square 30000-40000$

$\square$ 20000-30000

$\square 10000-20000$

$\square 0-10000$

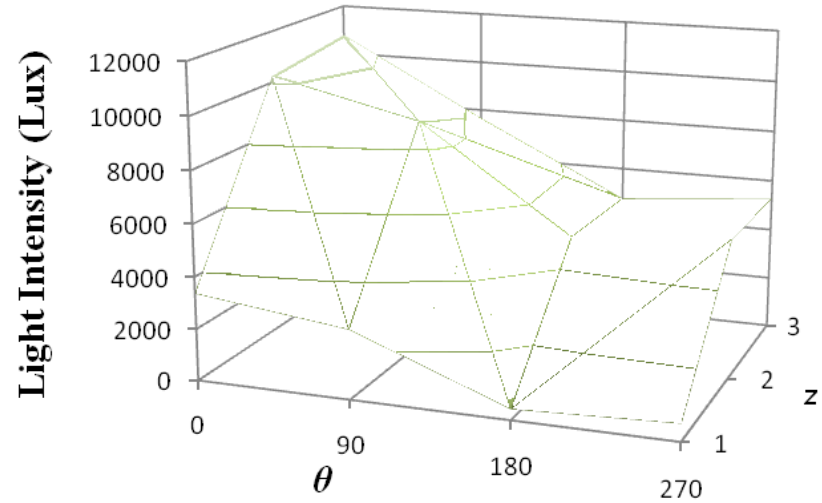

$\square 10000-12000$

$\square 8000-10000$

$\square 6000-8000$

$\square$ 4000-6000

口2000-4000

口 0-2000

Figure 2. Light intensities measured for reactor 1 (top) and reactor 2 (bottom). 

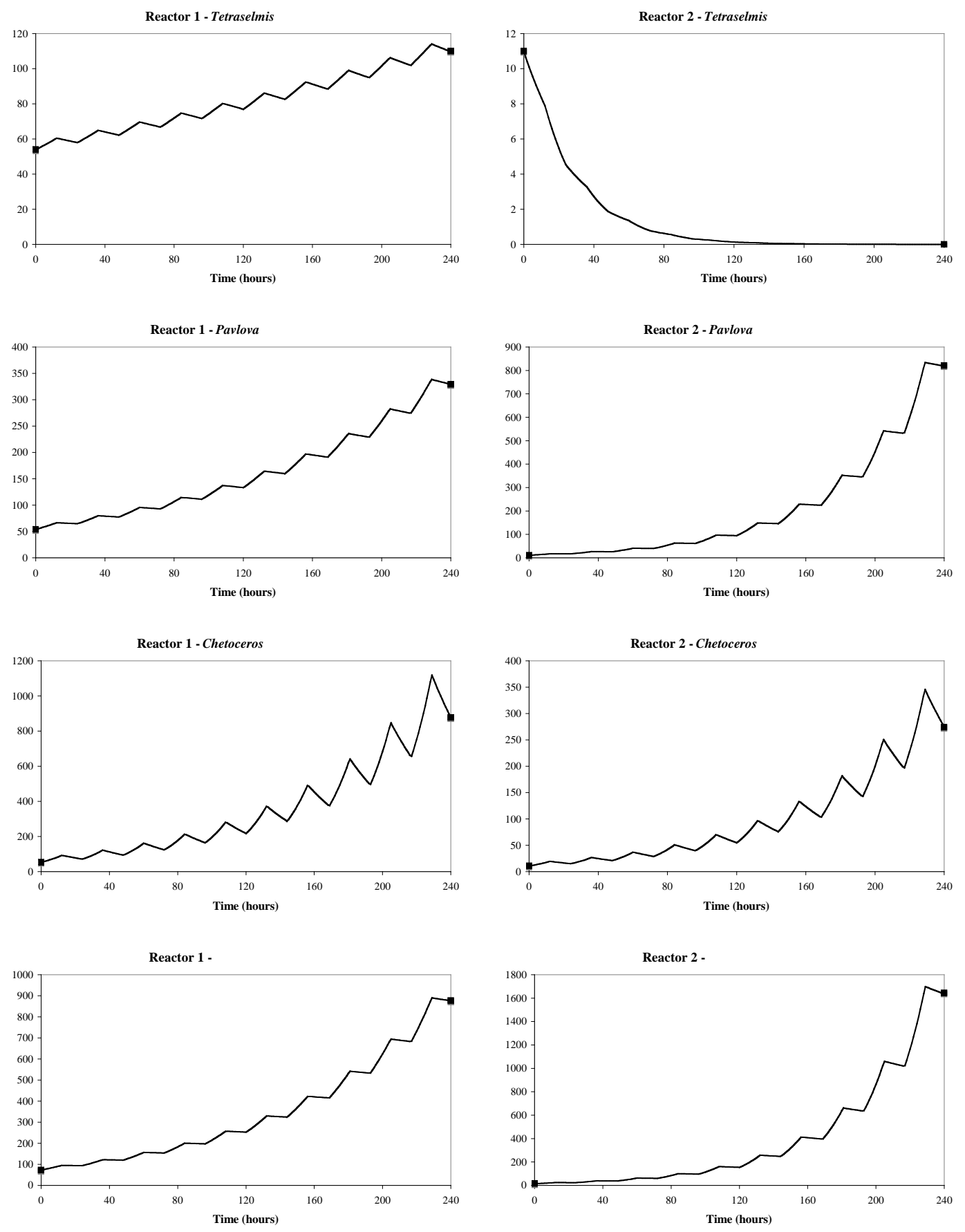

Figure 3. Predicted $(-)$ and measured $(\square)$ concentrations of the four microalgae species used in the leachate. Results for reactor 1 shown in left column and results for reactor 2 shown in right column. 

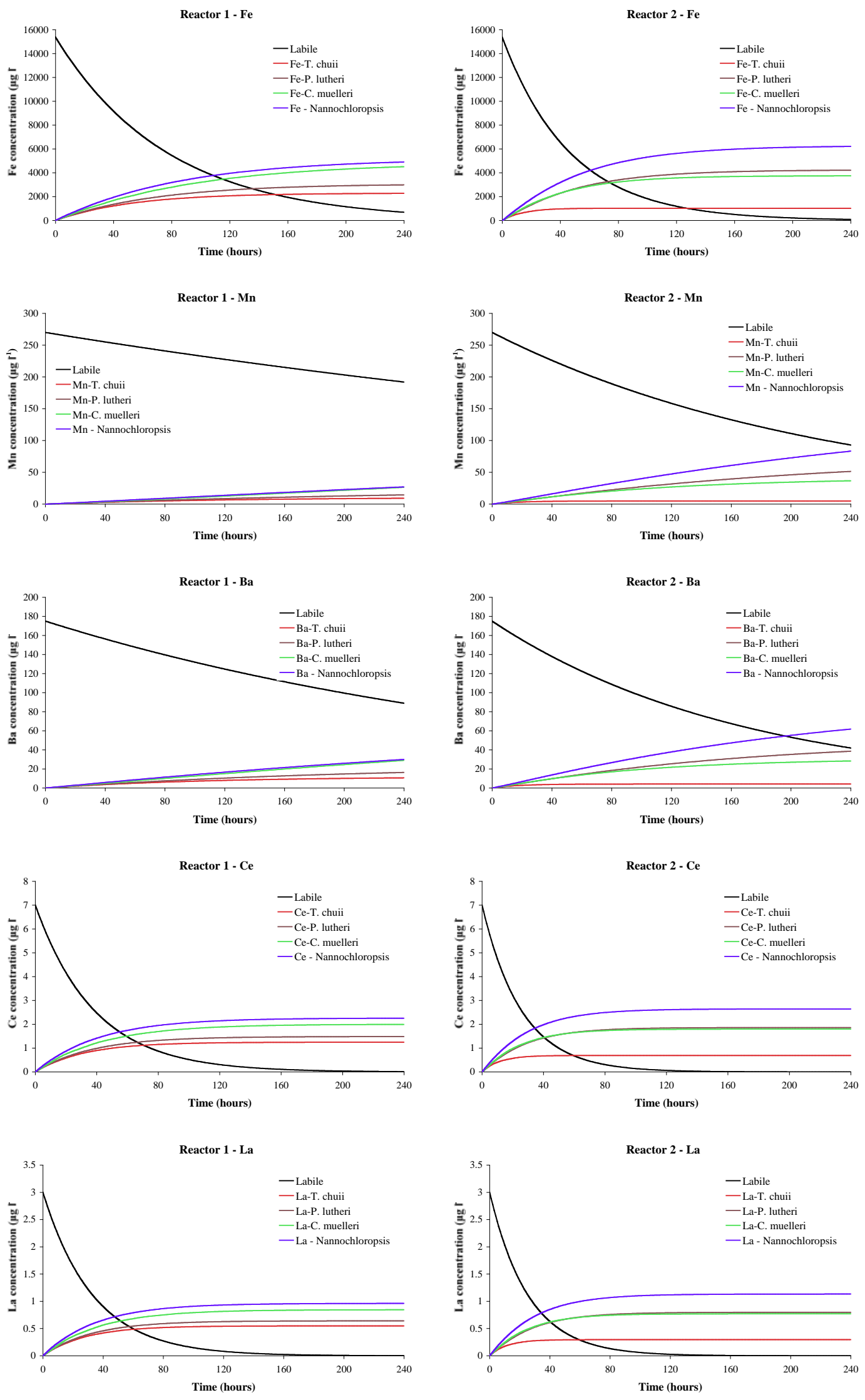

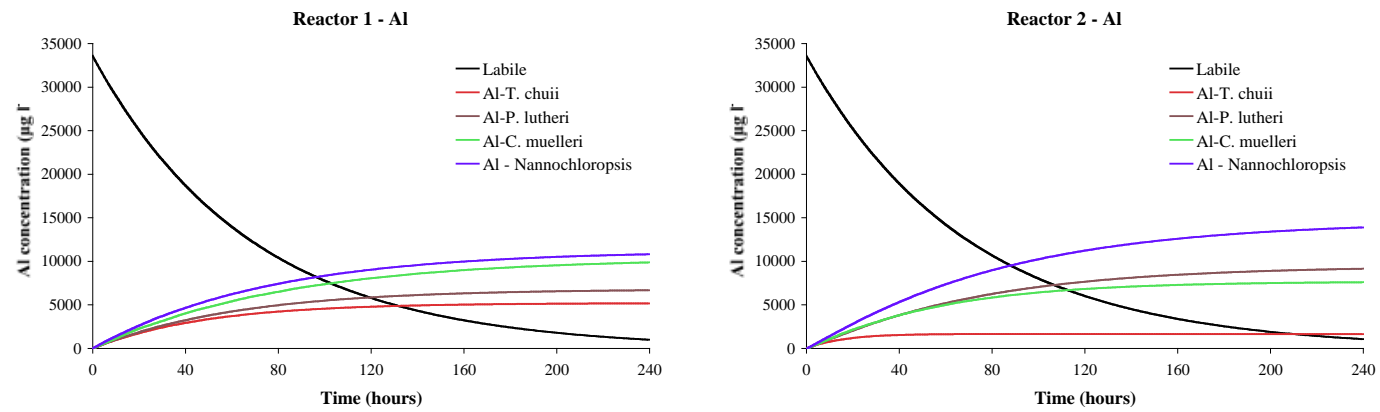

Figure 4. Predicted metal adsorption kinetics 

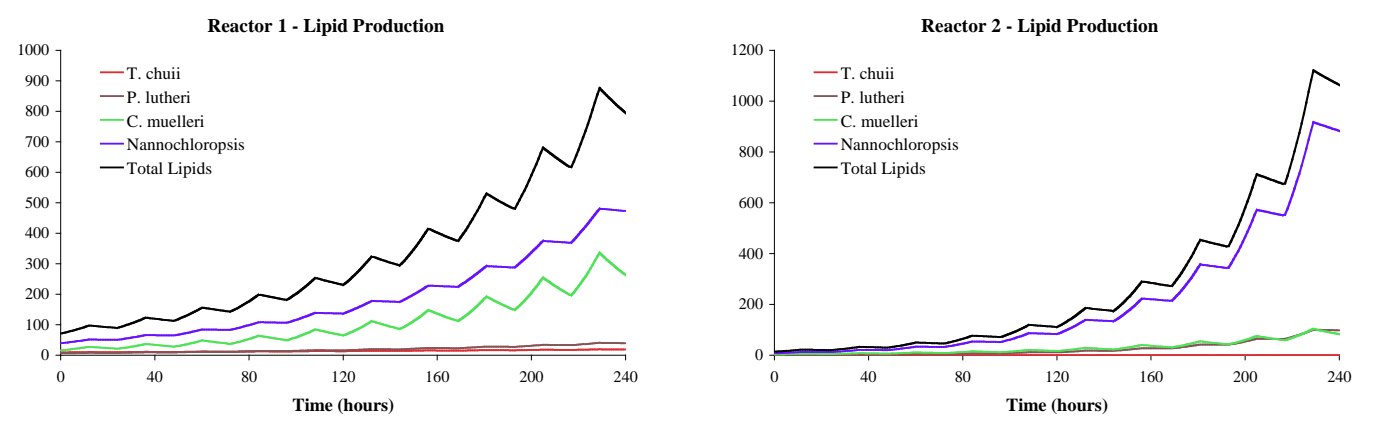

Figure 5. Predicted lipid production for each of the four microalgae species 